\title{
Enem: motivações e expectativas de estudantes da rede pública estadual de Sergipe
}

\author{
Enem: motivations and expectations of students from public schools from Sergipe State
}

\author{
R. M. K. Freitag ${ }^{1}$, R. R. Quirino', V. R. Andrade ${ }^{1}$, I.S. Silva ${ }^{1}$, J. L. Santos ${ }^{1}$ \\ ${ }^{1}$ Grupo de Estudos em Linguagem, Interação e Sociedade. Departamento de Letras Vernáculas, Universidade Federal \\ de Sergipe, 49100-000, São Cristóvão-Sergipe, Brasil \\ *rkofreitag@uol.com.br
}

(Recebido em 18 de novembro de 2016; aceito em 19 de abril de 2017)

\begin{abstract}
Este trabalho visa identificar quais as motivações que levaram os estudantes do Colégio Estadual Atheneu Sergipense e do Colégio Estadual Ministro Petrônio Portela, da rede pública estadual de Sergipe, a realizar o Exame Nacional do Ensino Médio, o Enem, de 2015, avaliando suas expectativas prévias e posteriores à aplicação da prova. Os métodos adotados para a efetivação deste estudo foram a realização de entrevistas e aplicação de questionários a 114 estudantes que realizaram a prova do Enem, em dois momentos: antes e depois da realização do exame. Os resultados apontam que, embora o Colégio Estadual Atheneu Sergipense seja reconhecido como um colégio de excelência, a motivação dos estudantes está relacionada ao seu interesse individual, e a família é a principal motivadora dos estudantes do Colégio Estadual Ministro Petrônio Portela.

Palavras-chave: Enem, Expectativas, Motivações
\end{abstract}

This paper aims to identify what are the motivations that led student from Colégio Estadual Atheneu Sergipense and Colégio Estadual Ministro Petrônio Portela, two public schools of Sergipe State, to take the Enem assessment in 2015, in order to measure the previous and post expectations of these students regarding the test. The methodology were constituted by interviews and tasks to 114 students that applied the Enem, from both schools, in two times: before and after the test. The results point that, although the Colégio Estadual Atheneu Sergipense is regonized as a excellence school, the motivation of their students are the individual interesting, and the family is the major motivation of students from Colégio Estadual Ministro Petrônio Portela.

Key-words: Enem, Expectations, Motivations.

\section{INTRODUÇÃO}

O Exame Nacional do Ensino Médio (Enem) tem ocupado um espaço de suma importância na vida escolar dos estudantes brasileiros. Criado em 1998, o exame inicialmente tinha o objetivo de avaliar o desempenho do estudante ao fim da etapa final da educação básica; e desde 2009, é utilizado como critério de seleção a vagas na educação superior em instituições públicas e privadas. Os resultados do Enem possibilitam ao estudante a participação em programas governamentais, dentre os quais: Sistema de Seleção Unificada (Sisu), sistema gerenciado pelo Ministério da Educação, no qual instituições públicas de ensino superior podem oferecer vagas para candidatos participantes do Enem; Programa Universidade para Todos (ProUni), criado pelo governo federal em 2004 com o objetivo de conceder bolsas de estudo integrais e parciais de $50 \%$ em instituições privadas de educação superior, em cursos de graduação e sequenciais de formação específica, a estudantes brasileiros sem diploma de nível superior; e Programa de Financiamento Estudantil (Fies), destinado a financiar a graduação na educação superior de estudantes matriculados em instituições privadas. Assumindo a função dos antigos exames vestibulares, o Enem passou de 157,2 mil inscritos na primeira edição, em 1998, para a marca 7.746.057 candidatos em 2015 [1, 2, 3, 4].

Em 2013, a Universidade Federal de Sergipe adotou como critério de seleção a nota obtida no Enem e, em 2014, aderiu ao Sisu. O fato de o Enem ser a principal forma de acesso às 
universidades públicas que aderiram ao Programa de Apoio a Planos de Reestruturação e Expansão das Universidades Federais (Reuni) e que têm o Sisu como forma de seleção tem motivado particularmente os estudantes da escola pública a se inscreverem no exame.

Por motivação, entendemos aquilo que move uma pessoa ou que a põe em ação ou a faz mudar de curso [5]. Na vida estudantil, tal fator é o que dá impulso aos alunos para que alcancem bons resultados em atividades escolares, o que pode incluir a realização da prova do Enem e de exames vestibulares. A motivação não se limita apenas à iniciativa própria, mas também envolve o contexto ao qual o indivíduo está inserido: ambiente escolar, familiar e outros.

A motivação pode ser gerada a partir de estímulos intrínsecos e extrínsecos. Na escola, um estudante é intrinsecamente motivado quando se mantém na tarefa pela atividade em si, um aluno é extrinsecamente motivado quando o seu objeto em realizar dada tarefa é obter recompensas externas, materiais ou sociais [6]. A escola assume um papel global no componente motivacional e a relação aluno-professor-escola deve ser tomada como ponto de partida para entender os fatores que levam o aluno a sentir-se motivado ou desmotivado. Fatores como sexo, idade, classe social, oportunidades educacionais, experiências sociais e clima institucional influenciam na motivação, ocasionando muitas vezes o baixo rendimento escolar, a depender da realidade na qual o indivíduo se encontra.

A escola deve ser motivadora; evidentemente, a ocorrência de crises institucionais é constante, envolvendo indivíduos que nela estão inseridos. Não existe instituição sem conflitos, mas solucioná-los é papel da escola. Se o aluno está inserido num ambiente sem aceitação, que o proporciona alguma espécie de conflito ou trauma acabará desmotivado, afetando seu desempenho [7]. No entanto, embora se atribua todas as tarefas ligadas à educação à escola, a motivação inicial é desencadeada pelo ambiente familiar; é a família o pilar mais importante no desenvolvimento e decisões do indivíduo. Família e escola são principais motivadoras para o desenvolvimento do indivíduo.

Considerando o Enem um exame que ao mesmo tempo avalia a qualidade do ciclo final da educação básica e possibilita acesso à educação superior, identificar os agentes motivadores dos estudantes para realizar o exame pode auxiliar na tomada de decisões de gestores e professores nas escolas, no que tange às políticas educacionais e práticas pedagógicas.

Foram selecionadas duas instituições públicas estaduais em Aracaju/SE, cada uma com um perfil diferenciado de estudantes: o Colégio Estadual Atheneu Sergipense e o Colégio Estadual Ministro Petrônio Portela. O Colégio Estadual Atheneu Sergipense, no centro, foi fundado em 1870, e passou por uma série de mudanças até tornar-se o que é hoje: um centro educacional de excelência de funcionamento integral que abriga alunos do ensino médio $[8,9]$. Destaca-se entre as escolas públicas por seus bons resultados nas provas do Enem no cenário estadual. No exame de 2014, alcançou o segundo lugar dentre as escolas públicas do estado de Sergipe, sendo a primeira da rede estadual, com média de 526,72 pontos nas provas objetivas e 578,6 na redação (a escola pública com a maior nota foi o Instituto Federal de Sergipe, escola pública da rede federal, com média 578,71 nas provas objetivas e 615,65 na redação). Este fato, aliado à sua condição de instituição pública, é o que atrai alunos de diversos municípios e condições financeiras, segundo a coordenação da escola. Já o Colégio Estadual Ministro Petrônio Portela, no bairro Augusto Franco, foi fundado em 1983, mesma época em que o bairro. Recebe alunos dos níveis de ensino fundamental e médio. Seu corpo discente provém, principalmente, das imediações do colégio e bairros próximos. No exame de 2014 do Enem, a escola obteve a média de 472,15 pontos nas provas objetivas e 424,74 na prova de redação. Observe-se que a nota média dos estudantes do Colégio Estadual Ministro Petrônio Portela está abaixo da média exigida para os pleiteantes de certificação de ensino médio, que é de 500 pontos $[1,3,5]$.

A diferença de público-alvo e a diferença de notas obtidas pelos estudantes nas escolas pode ser justificada pelas motivações e expectativas dos estudantes? A fim de responder a esta questão, foi realizada a investigação de campo nas instituições escolares, com estudantes que realizaram o exame do Enem em 2015. Esta investigação está vinculada ao projeto "Desenvolvimento de tecnologias sociais para formalização e ressignificação de práticas culturais em Aracaju/SE", financiado pelo edital Desenvolvimento de Ciência e Tecnologia na Educação Básica (CTI-EB) CAPES/FAPITEC/SE 05/2014, e os resultados visam subsidiar o planejamento de atividades de acordo com as demandas das escolas envolvidas. 


\section{MATERIAL E MÉTODOS}

A coleta de campo foi realizada por meio de gravação de áudio de entrevistas e aplicação de um instrumento de coleta de dados aos estudantes das escolas envolvidas que realizaram a prova do Enem em 2015, em dois momentos: na semana prévia à aplicação da prova e na semana posterior. O recorte temporal visou mensurar a expectativa e a avaliação do estudante em relação ao seu desempenho no exame. No entanto, em função de intercorrências do calendário escolar, a aplicação dos instrumentos de coleta escritos não foi satisfatoriamente produtiva no Colégio Estadual Ministro Petrônio Portela; por isso, foram utilizados apenas os dados das entrevistas. No Colégio Estadual Atheneu Sergipense foi possível realizar as entrevistas e aplicar os instrumentos de coleta escritos. Devido a essa restrição metodológica, os resultados são apresentados separadamente.

A seleção dos participantes foi feita pela abordagem direta, em contato pessoal. Os estudantes eram abordados individualmente e convidados a colaborar voluntariamente com a investigação. $\mathrm{O}$ requisito para a inclusão na pesquisa era: a) ser regulamente matriculado nos $2^{\circ}$ e $3^{\circ}$ anos do colégio e b) estar inscrito no Enem 2015.

Após a coleta de campo, os dados foram submetidos ao procedimento de validação, que consistiu na checagem das informações de identificação, qualidade do áudio das entrevistas e preenchimento completo dos instrumentos de coleta. Participaram 44 estudantes dos segundos e terceiros anos do ensino médio do Colégio Estadual Atheneu Sergipense; foram validados para a amostra 33 entrevistas e 43 instrumentos de coleta. No Colégio Estadual Ministro Petrônio Portella, foram realizadas 70 entrevistas com estudantes dos segundos e terceiros anos do ensino médio, sendo validadas 21 gravações da primeira coleta e 49 gravações da segunda coleta.

\section{RESULTADOS E DISCUSSÃO}

Inicialmente, no primeiro momento da coleta de dados (pré-Enem), os sujeitos da pesquisa foram inquiridos sobre o motivo pelo qual escolheram a escola para cursar o ensino médio. $\mathrm{O}$ objetivo da pergunta era saber se a escolha da escola estava relacionada à qualidade de ensino ofertada pelo colégio ou pela proximidade da residência (Figura 1).

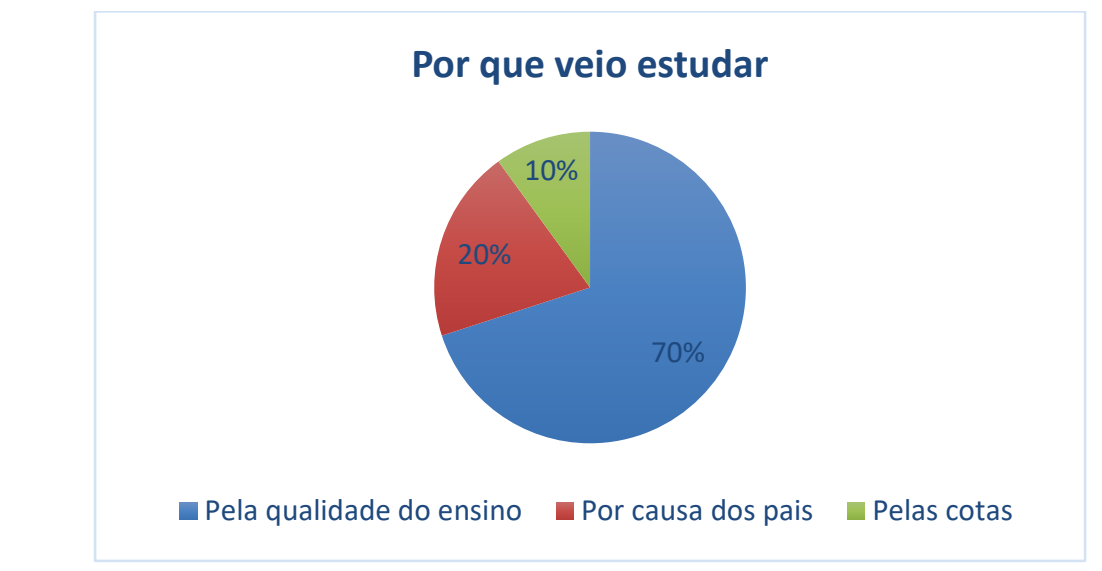

Figura 1. Porquê da escolha do colégio. Colégio Estadual Atheneu Sergipense.

Dentre os alunos entrevistados, $70 \%$ disseram ter decidido estudar no Colégio Estadual Atheneu Sergipense devido à sua qualidade de ensino. Os outros dividiram-se entre ter vindo estudar na escola por conta dos pais e também pelo critério de cotas de escola pública, adotado na seleção da Universidade Federal de Sergipe. A motivação pelo incentivo das cotas é uma questão relativamente complexa, que vem emergindo nos últimos anos, especialmente depois da adoção de critérios e reserva de vagas na educação superior para egressos da escola pública. Embora não existam estatísticas oficiais, há relatos de casos de estudantes simultaneamente matriculados em uma escola pública, como o Colégio Estadual Atheneu Sergipense, e em uma escola privada. Esta 
questão precisa de um tratamento particularizado por parte dos gestores, na medida que interfere nos resultados de avaliação da educação básica [1].

Considerando o percentual de estudantes que escolheram a instituição por conta de sua boa fama, por ser um centro de experimental, buscamos, então, saber se isso reflete na preparação dos alunos para o Enem. Aos mesmos estudantes foi feita a seguinte pergunta: Sente-se preparado(a) para o Enem? (Figura 2).

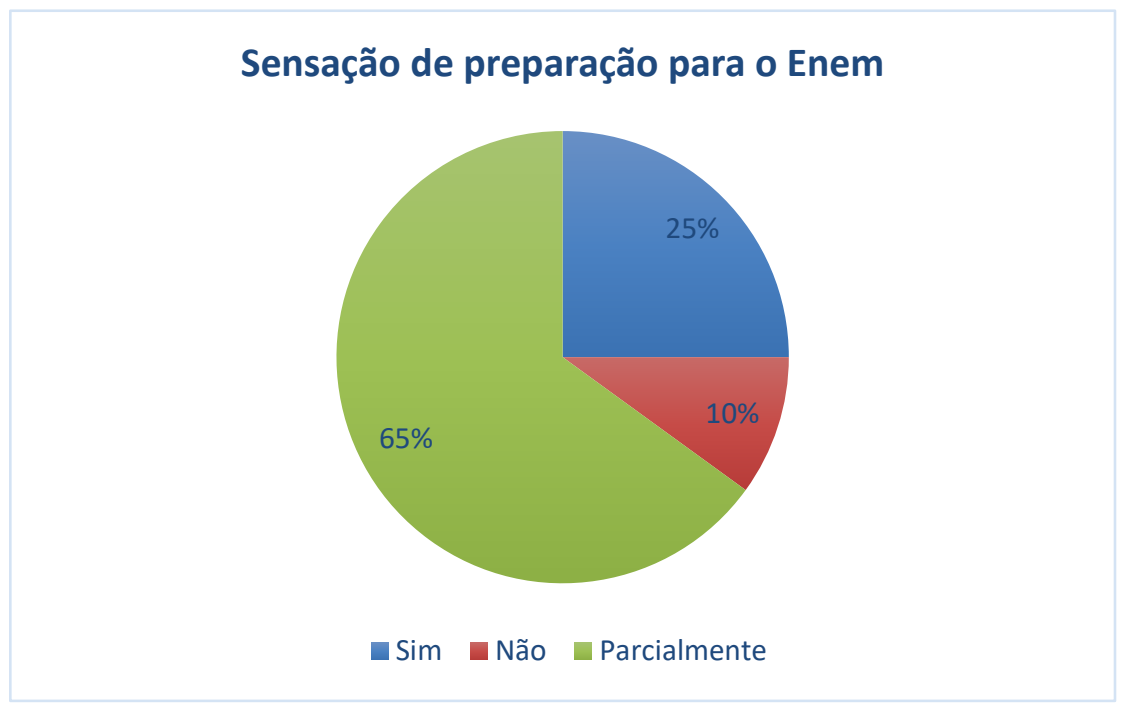

Figura 2: Preparação para o Enem. Colégio Estadual Atheneu Sergipense.

A insegurança na preparação para o exame está presente na resposta de $65 \%$ dos sujeitos, que não se sentem totalmente preparados para o exame. O motivo para a insegurança pode estar relacionado ao interesse individual e à falta de suporte na escola para a preparação da prova, como podemos verificar no excerto (1):

(1) Ambos... minha parte que eu acho que apesar do colégio não oferecer um... uma estrutura não... digamos não oferecer muitos simulados não oferece pra tirar dúvidas não foca mais no Enem apesar deles dizerem que sim... e por minha parte que não vou atrás do que não tem no colégio (Aluno 3, Colégio Estadual Atheneu Sergipense)

$\mathrm{O}$ modelo de ensino implantado nas escolas estaduais ainda não corresponde, assim, às competências exigidas pela prova do Enem: "Em relação à matriz curricular, ainda existem muitas lacunas. Não houve uma adaptação coerente que de fato atenda às competências e às habilidades pedidas para a prova do Enem. Algumas escolas têm se empenhado em desenvolver trabalhos durante todo o ano letivo, através dos sábados letivos, reforços em horários opostos ao ensino regular; no entanto, outras, apenas às vésperas da prova, algo ineficaz, uma vez que tais competências e habilidades requerem prática e disciplina e outras instituições permanecem sem nenhuma adaptação ou criação de recursos" [10].

A greve dos professores foi outro fator explanatório presente nas entrevistas com os estudantes, como podemos verificar nos excertos (2) e (3):

(2) Não posso dizer que sim nem posso dizer que não... porque ...como teve essas greves tal e tudo... aí... mas eu posso dizer que sim uma parte... só vou ter certeza lá na hora (Aluno 7, Colégio Estadual Atheneu Sergipense)

(3) Dos dois... um pouco dos dois... porque o fato de você não ter aula é o fato que seu corpo relaxa e... $e$ isso é vacilo da pessoa por não poder seguir esse caminho de resistência de ter estudado mesmo tendo greve (Aluno 5, Colégio Estadual Atheneu Sergipense)

A cobrança de iniciativa própria para se esforçar nas atividades escolares pode estar interligada ao cansaço que os estudantes alegam sentir ao final do ensino médio, aliado também às constantes 
greves na rede pública. Como vimos no excerto (3), torna-se desgastante para o aluno que vem se preparando para um exame a volta às aulas após uma longa paralisação. Os estudantes, porém, não taxaram o ensino oferecido pela escola como motivo da falta de segurança em relação à prova do Enem. O papel motivador da instituição escolar foi classificado como satisfatório para os alunos que foram entrevistados antes do exame.

A motivação é entendida como um dos aspectos determinantes do processo de aprendizagem, pois nela estão presentes fatores psicológicos que levam à escolha e/ou iniciativa de uma atividade, bem como a persistência em fazê-la, o emprego de esforço e de recursos pessoais, como o tempo, energia, talento, conhecimento, entre outros [5].

Com o propósito de identificar quais os motivos que levaram os alunos do Colégio Estadual Atheneu Sergipense a realizarem o Enem 2015, o instrumento de coleta pré-Enem solicitava que os alunos assinalassem o que os levaram a realizar a inscrição no Enem. Foi constatado que o desejo de ingressar no ensino superior é o recorrente, com $48 \%$ das respostas (Figura 3).

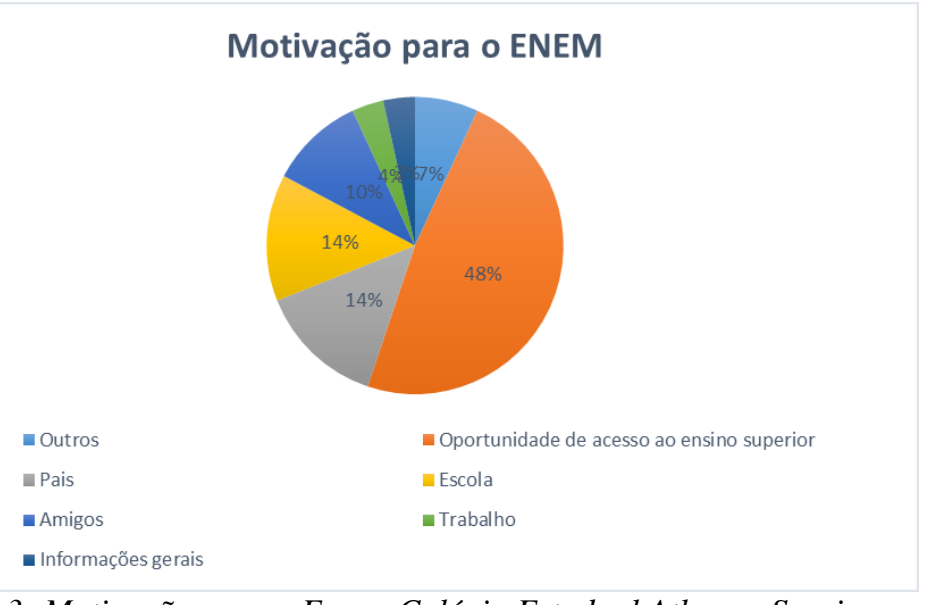

Figura 3: Motivação para o Enem. Colégio Estadual Atheneu Sergipense.

O desejo de ingressar no ensino superior é movido pelo interesse individual, sendo então uma motivação intrínseca do estudante. Pelas respostas, a escola e a família atuam também como incentivadoras da iniciativa dos estudantes: $14 \%$ dos 18 estudantes disseram que a família foi sua fonte de incentivo para a realização da prova. Esse número de alunos incentivados pela família mostra que a escola não é a única que deve cumprir com seu dever: "a participação dos pais significa visualizar a escola como um espaço democrático em que as pessoas podem exercer a sua cidadania" [11]. O envolvimento familiar no processo não só de ensino-aprendizagem como também no de motivação, inserindo na convivência familiar o incentivo para determinadas atividades, especialmente escolares, é um fator desencadeador da participação dos estudantes do Colégio Estadual Atheneu Sergipense no Enem.

O instrumento de coleta aplicado antes da realização do Enem 2015, continha uma questão que solicitava aos alunos que encaixassem seu nível de expectativas em relação ao exame, em que o nível 0 demonstraria total falta de expectativas e o nível 10 demonstraria alta expectativa para o exame. A partir dos resultados verificou-se um alto nível de expectativas em relação à prova (Figura 4). Dos 17 alunos, 95\% mostraram nível de expectativa entre os níveis 5 e 10, sugerindo uma preparação satisfatória, de tal forma a deixá-los seguros e confiantes para realizarem o exame e alcançar suas expectativas. 


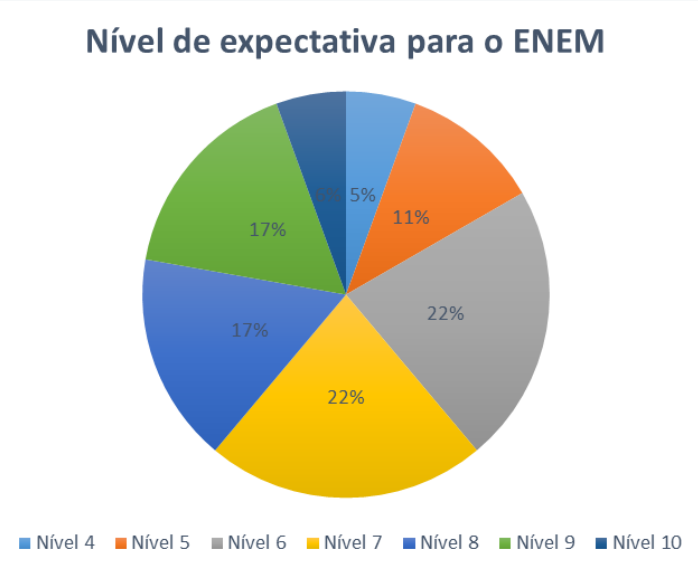

Figura 4. Nível de expectativas para o Enem. Colégio Estadual Atheneu Sergipense.

Após a realização do exame, $80 \%$ dos estudantes que responderam ao instrumento de coleta pós-Enem demonstraram uma sensação positiva, ou seja, se sentiam confiantes frente ao desempenho no exame, confirmando e/ou surpreendendo-se com o possível desempenho. A porcentagem de alunos desacreditados em relação ao exame é de 20\% (Figura 5).

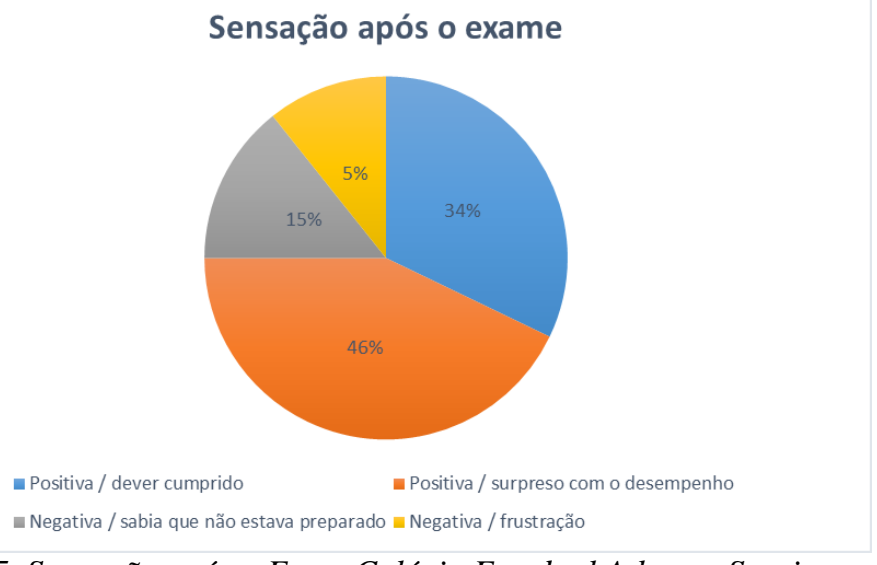

Figura 5. Sensação após o Enem Colégio Estadual Atheneu Sergipense.

A autoavaliação positiva em relação ao desempenho é atribuída ao interesse individual e a contribuição oferecida pela escola. Por fim, tendo a autoavaliação dos alunos em relação ao possível desempenho no exame, antes e depois de sua aplicação, possibilitou a comparação das expectativas que antecederam e sucederam a prova (Figura 6).

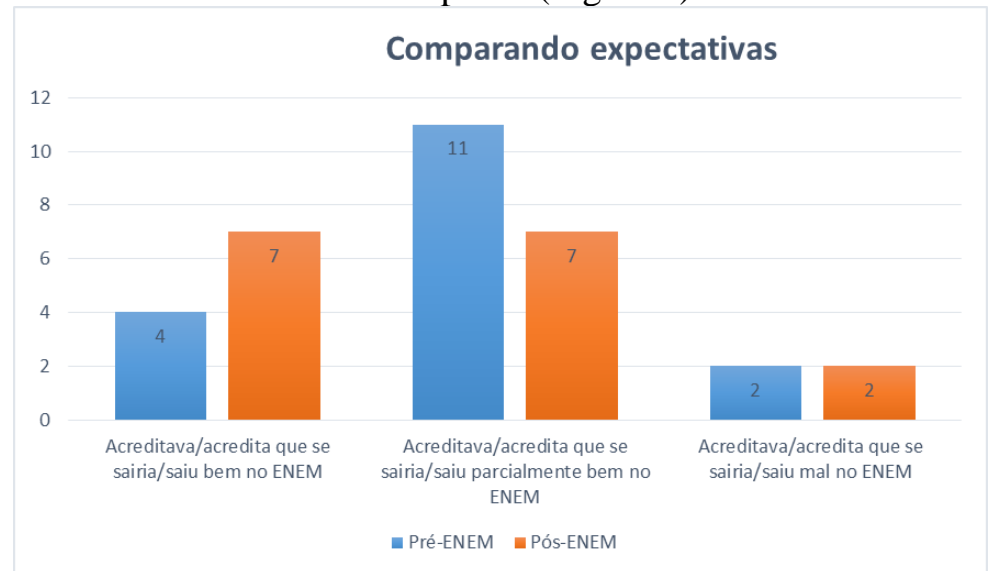

Figura 6. Comparativo das expectativas. Colégio Estadual Atheneu Sergipense.

A comparação entre a expectativa e a autoavaliação do estudante evidencia um aumento acentuado do número de alunos que acreditavam e acreditam ter tido um bom desempenho no exame. Houve também uma redução no número de alunos que acreditava/acreditam ter tido um 
desempenho parcialmente bom no exame. A mudança do cenário, de acordo com o testemunho dos estudantes nas entrevistas, se deve tanto à preparação quanto ao nível e tema da prova desse ano.

No Colégio Estadual Ministro Petrônio Portela, dentre os estudantes entrevistados, apenas 24\% afirmaram ter realizado o exame por si mesmo; os demais afirmaram ter realizado o exame por incentivos externos (Figura 7).

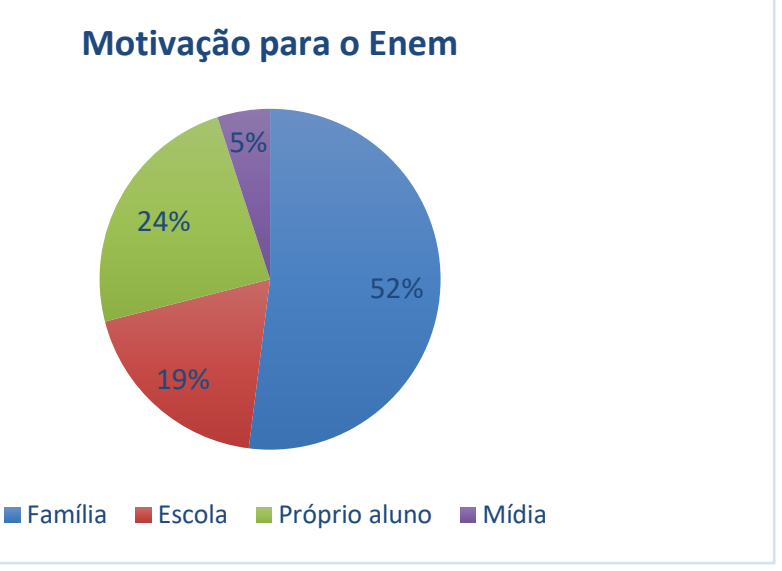

Figura 7. Motivação para o Enem. Colégio Estadual Ministro Petrônio Portela.

O ambiente familiar e a escola são de suma importância para o desenvolvimento cognitivo do aluno; no Colégio Estadual Ministro Petrônio Portela, a família aparece como principal fator motivador do aluno na realização da prova, com 52\%. A escola, por sua vez, principal formadora de conhecimento, foi pouco citada na amostragem.

O papel da escola fica mais evidente na análise da autoavaliação dos estudantes em relação ao seu preparo para a prova (Figura 8) e a percepção de preparação para a prova por parte da escola (Figura 9).

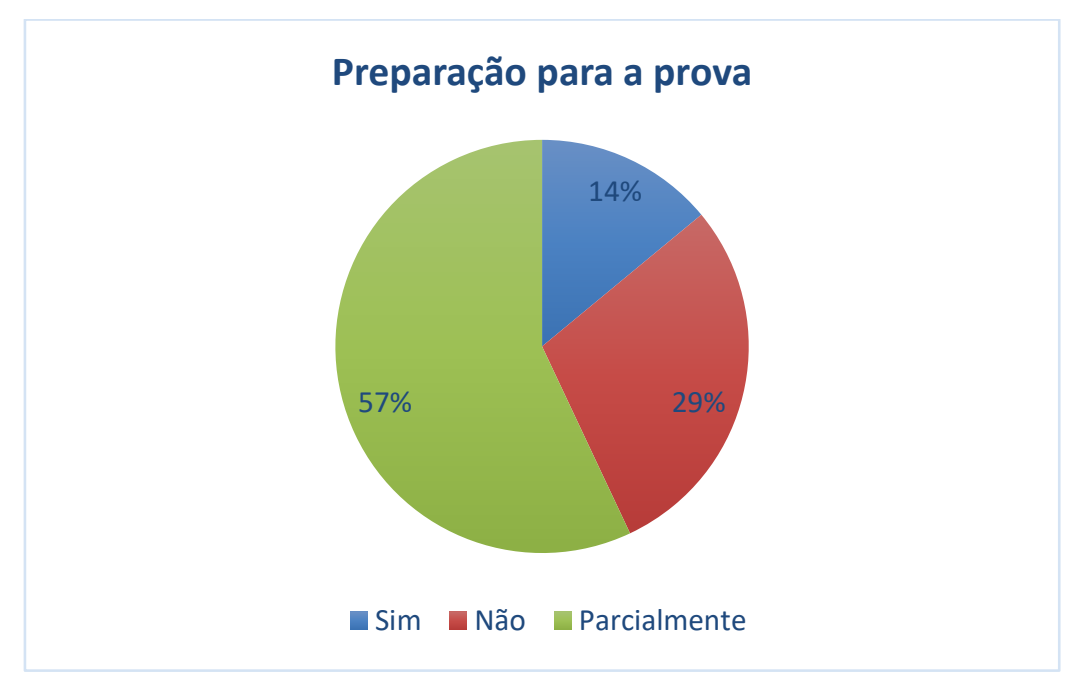

Figura 8. Autoavaliação da preparação para o Enem. Colégio Estadual Ministro Petrônio Portela.

Os estudantes não se sentem preparados para a realização da prova: não chega a $30 \%$ o contingente da amostra do Colégio Estadual Ministro Petrônio Portela que se sente preparado para realizar o exame. Este resultado é ligeiramente superior ao obtido no Colégio Estadual Atheneu Sergipense, em que o contingente de estudantes perfaz $24 \%$ do total da amostragem. Tal resultado pode ser atribuído pela percepção dos estudantes em relação às atividades propostas pela instituição escolar para o Enem: aulas extras, palestras, simulados e vídeos motivacionais foram listados como atividades realizadas pela escola e percebidas pelos estudantes como importantes para o preparo para o exame. No entanto, na percepção discente, mais ações poderiam ser realizadas (Figura 10). 


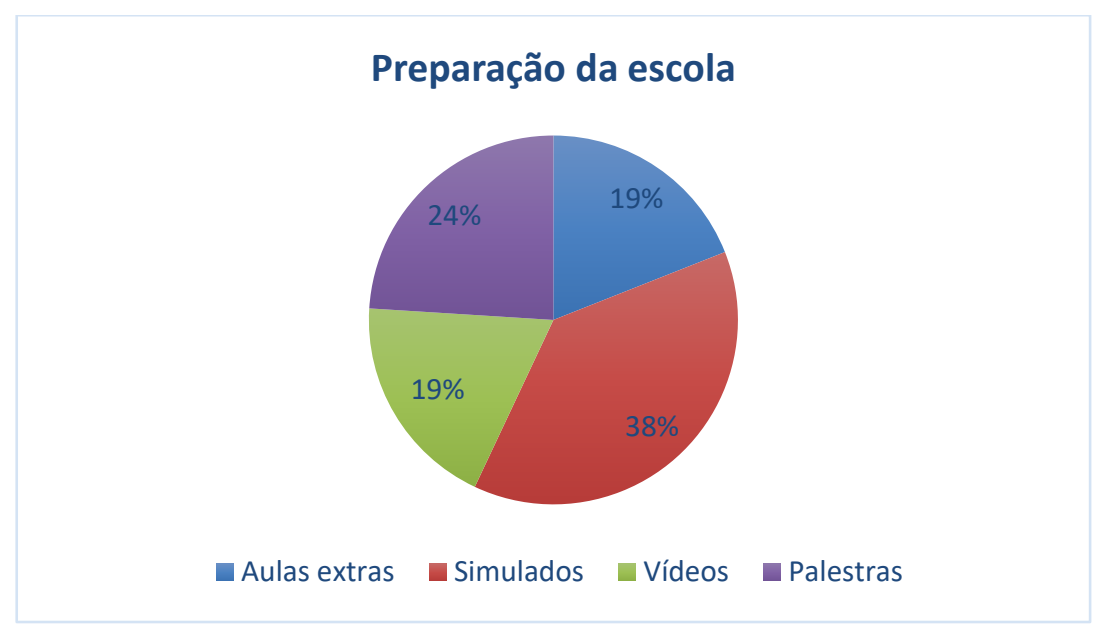

Figura 9. Preparação da escola para o Enem. Colégio Estadual Ministro Petrônio Portela.

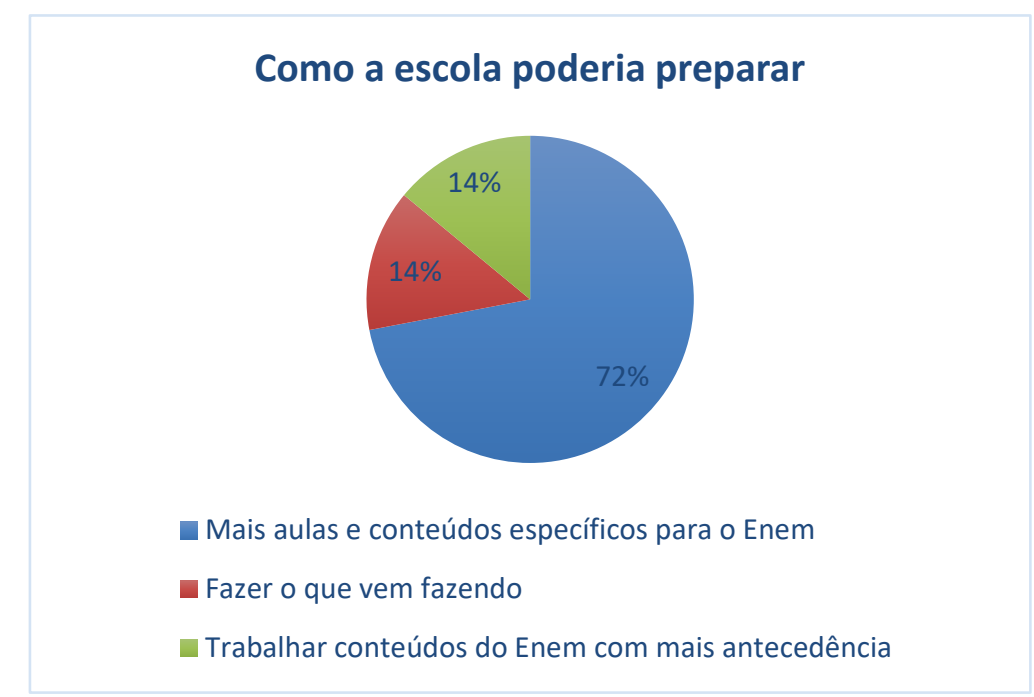

Figura 10. Outras formas de preparação da escola para o Enem.

Nas entrevistas, constatamos que, segundo os estudantes, embora atividades para preparação ao Enem sejam realizadas, são tardias, ou seja, ocorrem poucas semanas antes da aplicação da prova, como podemos observar nos excertos (4) e (5).

(4) Eu acho que eles poderiam elas (hes) eles poderiam colocar com mais antecedência as ati-essas atividades para a gente poder adquirir um pouco mais... para não fi-quando ficar muito próximo agora como está...né? já... perto do Enem a gente tenha um pouco mais... de experiência e até mesmo de conhecimento. (Aluno 4, Colégio Estadual Ministro Petrônio Portela)

(5) Que ela... poderia fazer melhor... eu acho que: em si... puxar um pouco mais do aluno... em si porque tipo... tem alguns alunos que são desinteressados para o Enem que até nem se inscreveram ou fingem que se inscrevem na-na verdade nem acabam nem indo... eles deveriam puxar mais o assunto do Enem e por não esque-não esquecer o assunto do colégio mas sim puxar mais... acho que se puxasse mais pelo assunto do Enem e mostrasse o que ele poderia disponibilizar... acho que o colégio deveria ter essa consciência porque o aluno iria se... <<vantagear >> mais entendeu? (Aluno 6, Colégio Estadual Ministro Petrônio Portela.) 
Diferentemente do vestibular tradicional, a prova do Enem é interdisciplinar e contextualizada $[1,2,4]$. Muitas vezes o aluno conhece o conteúdo abordado, mas a forma com que foi trabalhado em sala de aula, em matéria compartimentalizada, torna o estudante inseguro na hora de responder à questão. Nas entrevistas pós-Enem, todos os estudantes afirmaram ter identificado alguma questão cujo conteúdo foi abordado em sala de aula.

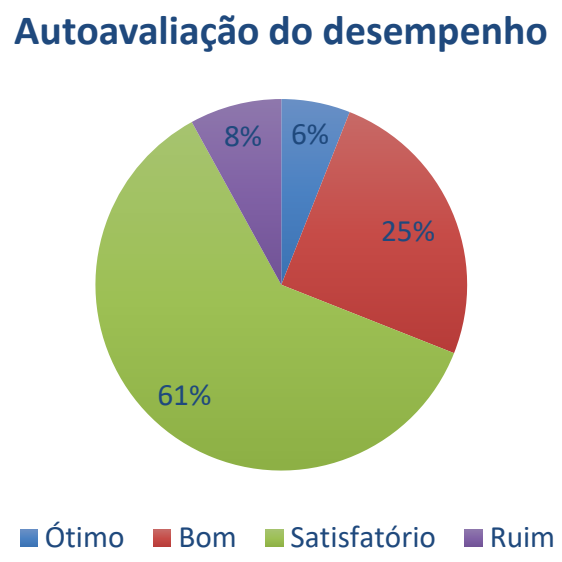

Figura 11. Autovaliação do desempenho no Enem. Colégio Estadual Ministro Petrônio Portela.

Os estudantes do Colégio Estadual Ministro Petrônio Portela apontam majoritariamente um desempenho satisfatório na prova, nas entrevistas pós-Enem, com $61 \%$, apenas $25 \%$ consideram ter um bom desempenho. Como contraponto, os estudantes do Colégio Estadual Atheneu Sergipense apontaram uma autoavaliação positiva em percentual muito superior.

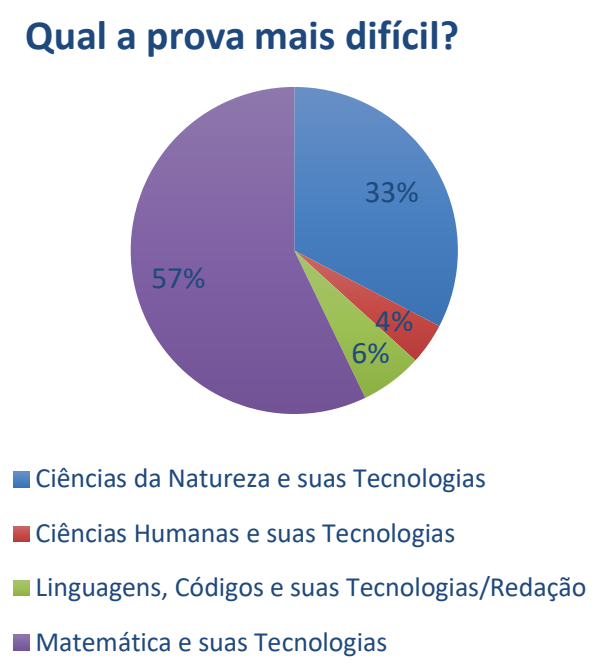

Figura 12. Dificuldade nas provas do Enem. Colégio Estadual Ministro Petrônio Portela.

Quanto à percepção de dificuldades, Ciências da Natureza e suas Tecnologias e Matemática e suas Tecnologias são as provas a que os estudantes mais atribuem grau de dificuldade, especialmente porque envolvem interpretação e desdobramento de fórmulas, que não podem ser resolvidas no "decoreba", como no tradicional vestibular. Estas provas são as que apresentam menor desempenho, de maneira geral, dentre as médias das instituições de ensino que participam do exame [3]. 


\section{CONCLUSÃO}

Sem motivação não há êxito em nenhuma tarefa. O Enem representa na vida dos estudantes da rede pública estadual de Sergipe, particularmente no Colégio Estadual Atheneu Sergipense e no Colégio Estadual Ministro Petrônio Portela, a oportunidade de acesso ao ensino superior.

O Colégio Estadual Atheneu Sergipense, destacando-se por seu diferencial de ensino voltado para o Enem, tem motivado os estudantes na realização do exame. Isso é confirmado na percepção de expectativas dos estudantes. Na visão dos alunos, não ter suporte na preparação para o exame os prejudica. Em outras escolas, como no Colégio Estadual Ministro Petrônio Portela, acontece o mesmo, afetando o preparo e desempenho dos alunos na prova. Identificamos que há diferença nos motivadores dos estudantes nas duas escolas: enquanto no Colégio Estadual Atheneu Sergipense a motivação maior é a do próprio estudante, no Colégio Estadual Ministro Petrônio Portela a motivação maior é a da família; tal resultado reflete de certo modo o público que as escolas atendem: o Colégio Estadual Atheneu Sergipense agrega alunos de diferentes bairros de Aracaju e até mesmo alunos residentes na Grande Aracaju, motivados pelo fato de ser um centro experimental e pela divulgação dos rankings de resultados do Enem; o Colégio Estadual Ministro Petrônio Portela atende à população do bairro e do seu entorno, com suas relações estabelecidas pela rede familiar. Enquanto o Colégio Estadual Atheneu Sergipense é caracterizado pela motivação intrínseca, o Colégio Estadual Ministro Petrônio Portela é caracterizado pela motivação extrínseca para a adesão ao Enem.

A identificação das diferenças de motivação requer que os gestores tomem diferentes encaminhamentos, em atenção às necessidades e demandas do corpo discente.

Esperamos que os resultados obtidos possam auxiliar para a elaboração de práticas no entorno escolar que estimulem o corpo estudantil a realizar atividades tal como o Enem, contribuindo, portanto, para o andamento do projeto "Desenvolvimento de tecnologias sociais para formalização e ressignificação de práticas culturais em Aracaju/SE", financiado pelo edital Desenvolvimento de Ciência e Tecnologia na Educação Básica (CTI-EB).

Apesar de o Enem alcançar grandes marcos, poucos estudos sobre a motivação dos alunos para realização desse exame têm sido realizados, principalmente com base nas instituições públicas de educação básica, estas que são as mais afetadas. Esses estudos são importantes, pois auxiliam a traçar metas e solucionar eventuais problemas, como é o intuito desta investigação.

\section{REFERÊNCIAS BIBLIOGRÁFICAS}

1. Alves FS. O que pensa o estudante sobre o Exame Nacional do Ensino Médio: Enem para quem? [dissertation]. São Cristóvão (SE): Universidade Federal de Sergipe, 2016. 97 p.

2. Andrade, SRJ, Freitag, RMK. A evolução do tratamento da variação linguística no Enem. Signum: Estudos da Linguagem, 2016;19(1):293-320.

3. Freitag RMK. A nota do Enem: acesso e permanência na Universidade Federal de Sergipe. In: Oliveira LE, Meneses, JS. (orgs.) (Re)pensando a licenciatura. São Cristóvão: Edufs; 2016. p. 75-90.

4. Silva L, Freitag RMK. Linguagem, interação e sociedade: diálogos sobre o Enem. João Pessoa: CCTA; 2015.

5. Bzuneck JA. A motivação do aluno: contribuições da psicologia contemporânea. Petrópolis: Vozes; 2004.

6. Neves ERC, Boruchovitch, E. A motivação de alunos no contexto da progressão continuada. Psicologia: teoria e pesquisa, 2004;20(1):77-85.

7. Novais MH. Psicologia do ensino-aprendizagem. São Paulo: Atlas; 1977.

8. Alves EMS. O Atheneu Sergipense: traços de uma história. Revista do Instituto Histórico e Geográfico de Sergipe, 2005;34(1):133-152.

9. Freitag RMK et alii. Avaliação e variação linguística: estereótipos, marcadores e indicadores em uma comunidade escolar. In: Freitag RMK, Severo CG, Görski EM (orgs.) Sociolinguística e política linguística: olhares contemporâneos. São Paulo: Blucher; 2016. p. 141-160.

10. Freitag RMK; Cunha FM; Santana JJ. O desempenho na prova do Enem da rede estadual de Sergipe. In: Silva L, Freitag RMK. (orgs.) Linguagem, interação e sociedade: diálogos sobre o Enem. João Pessoa: CCTA; 2015. p. 163-171.

11.Zanella A. Participação dos pais na escola: diferentes expectativas. Porto Alegre: ABRAPSOSUL; 1997. 